\title{
Movimento Humano em uma Perspectiva Psicossomática: Estudos de Judith Kestenberg ${ }^{1}$
}

\author{
Larissa Sato Turtelli \\ Maria da Consolação Gomes Cunha Fernandes Tavares \\ Universidade Estadual de Campinas
}

\begin{abstract}
RESUMO - Este artigo considera o movimento corporal humano contextualizado no mundo psíquico na visão de Judith Kestenberg, abordando: 1) as principais categorias de movimento identificadas por Kestenberg e os significados relacionados a elas; 2) as relações (afinidades e choques) desses padrões de movimento entre si; 3 ) as relações entre as preferências iniciais da criança por certos ritmos de movimento e seus padrões de movimento na vida adulta. O objetivo desta pesquisa foi apresentar os estudos de Kestenberg, os quais fornecem um conhecimento necessário para aqueles que buscam compreender o movimento corporal humano no contexto terapêutico.
\end{abstract}

Palavras-chave: psicomotricidade; movimento; imagem corporal; psicanálise.

\section{Human Movement from a Psychosomatic Perspective: Judith Kestenberg's Studies}

\begin{abstract}
This paper considers Judith Kestenberg's approach to the psychic contextualization of human body movements, presenting: 1) the main movement categories identified by Kestenberg and their meanings; 2) the relations (affinities and shocks) within these movement patterns; 3 ) the relations between the initial preferences of a child for certain rhythms of movements and his/her movement patterns in adult life. The aim of this research was to present Kestenberg's studies, which offer a necessary knowledge to those willing to comprehend human body movement in a therapeutic context.
\end{abstract}

Key words: pychomotility; movement; body image; psychoanalysis.

O movimento de cada ser humano é único nas suas pequenas variações e combinações. Essa individualidade provém de uma realidade na qual os fatores psicológicos e fisiológicos estão fundidos. Retornando às funções básicas do movimento humano, chega-se à sua relação com os instintos de sobrevivência: o movimento é a forma de relação do ser humano consigo mesmo e com o meio, é a forma pela qual o ser humano se expressa, se protege, busca alimento e desempenha suas funções vitais (Damásio, 1994/1996; Schilder, 1950/1999).

Muitas vezes, nas pesquisas sobre o movimento corporal humano, é feita uma cisão entre os aspectos fisiológicos e psicológicos. Essa separação, embora seja necessária para determinadas investigações do movimento, em outros momentos precisa ser superada: no estudo do movimento do ser humano é preciso considerar também o "humano" que há ali.

Penna (1989) fala sobre a função adaptativa do movimento e ressalta a importância de, no contexto terapêutico, ser abordado de forma integrada o "duplo aspecto do indivíduo perante o meio e perante si mesmo, sem separar as variáveis fisiológicas e psicológicas no estudo da adaptação a um determinado ambiente físico e cultural" (p. 4).

1 Agradecemos à Fundação de Amparo à Pesquisa do Estado de São Paulo (FAPESP) pelo financiamento à pesquisa que originou este artigo (Processo 01/01510-5). Uma versão preliminar deste trabalho fez parte da dissertação de mestrado da primeira autora, defendida em 2003 na Universidade Estadual de Campinas (UNICAMP).

2 Endereço: Rua Dr. José Ramos de Oliveira Júnior, Lt. 24, Qd. H, Bairro Vale das Garças, Campinas, S.P, Brasil 13085-751.E-mail: l.turtelli@iar. unicamp.br
Judith Kestenberg (1910-1999) foi uma estudiosa que se dedicou a ter uma compreensão profunda e pormenorizada do movimento, procurando considerar de forma integrada os vários aspectos envolvidos no ato do mover. O interesse de Kestenberg pelo estudo do movimento surgiu do seu trabalho com crianças e com as relações pais e filhos. A autora destaca a importância do estudo do movimento no contexto terapêutico e observa que, na maioria dos casos, as considerações sobre os movimentos nesse contexto são feitas de forma predominantemente intuitiva.

Direcionada por essas inquietações, Kestenberg desenvolveu um método de codificar os movimentos e de interpretar seus significados. Também desenvolveu um modo de notação dos movimentos. Esse método foi chamado de Kestenberg Movement Profile (KMP). Sua codificação foi derivada do método de Laban (1879-1958), de sua noção de esforço. Laban (1971/1978) denominou esforço o "ponto de origem e aspecto interior" dos movimentos humanos (p. 51). Kestenberg subdividiu o esforço de Laban em fluxos de tensão, precursores de esforço e esforço. A pesquisadora utiliza também a categorização dos movimentos segundo atributos de forma, observando nos movimentos os fluxos de formas, modelagens do espaço em direções e modelagens do espaço em planos.

No KMP é feita uma diferenciação minuciosa entre qualidades de movimento que em um primeiro momento poderiam parecer iguais. Amighi, Loman, Lewis e Sossin (1999) consideram que:

[as] qualidades de movimento codificadas através do KMP refletem estilos individuais de aprendizagem e cognição, 
expressões de necessidades e sentimentos, modos de relacionamento, estilos de defesas e dinâmicas para lidar com o meio ambiente. Os analistas com orientação psicanalítica podem usar o KMP para acessar informações sobre as pulsões, as relações com os objetos, o desenvolvimento do ego, o superego e os mecanismos de defesa. Entretanto o KMP também é acessível para aqueles com outras orientações e pode ser usado para atingir uma variedade de objetivos (p. 2, tradução nossa).

Amighi e cols. (1999) falam da importância dos pesquisadores que estudam o movimento moverem-se também. Relatam que, no grupo de pesquisas inicial criado por Kestenberg, os psiquiatras tiveram que ter aulas de movimento para aprenderem sobre as sensações de seus próprios corpos, pois essas sensações são importantes para processar as informações dos movimentos dos corpos dos outros. Esse processo é o que alguns autores chamam de "sentido cinestésico".

Stinson (1995) considera que o sentido cinestésico refere-se à sensação interna dos movimentos e das tensões. Esse sentido, combinado com a visão, nos permite conectar com os outros, tanto em condições diretamente relacionadas ao movimento, como compartilhar emoções em um nível sensório-motor.

Kestenberg enfatizava a observação do movimento por meio da identificação cinestésica, isto é, mediante traduzir as qualidades de movimento observadas em outra pessoa para o próprio corpo. Segundo Amighi e cols. (1999), esse é um processo necessário na pesquisa do movimento e deve ser usado quando um pesquisador atenta para os movimentos de uma pessoa. Eles observam que é mais fácil sintonizar com a tensão muscular de uma outra pessoa pelo uso do contato físico, porém uma pessoa também pode sentir em seu corpo a tensão muscular de outra pessoa apenas pela observação.

O método de Kestenberg para codificar e interpretar o movimento provê uma abordagem coerente para o entendimento dos significados que podem ser atribuídos a padrões específicos de movimento. Ele aborda o movimento com um enfoque primeiramente intrapessoal e, apenas em segundo plano, dirige-se à comunicação não verbal. Centra-se no significado intrínseco dos padrões de movimento, ligando-os principalmente a processos do desenvolvimento e experiências psicológicas. Busca assim informar sobre as dinâmicas e estruturas internas de um indivíduo (Amighi \& cols., 1999).

A seguir serão apresentadas 1) as principais categorias de movimento identificadas por Kestenberg e os significados relacionados a elas; 2) as relações (afinidades e choques) desses padrões de movimento entre si; 3 ) as relações entre as preferências iniciais da criança por certos ritmos de movimento e suas influências nos padrões de movimentos da vida adulta. A base para essas considerações foi o estudo dos livros: Children and Parents (Kestenberg, 1975), The Role of Movements Patterns in Development (Kestenberg \& Sossin, 1979) e The Meaning of Movement (Amighi \& cols., 1999).

\section{Ritmos do Movimento}

Para Kestenberg, as formas básicas e onipresentes de ritmicidade, que são parte do aparato motor congênito, consistem em repetições de mudanças na tensão (ritmos de fluxo de tensão) e mudanças na forma do corpo (ritmos de fluxo de forma). Essas mudanças podem ser alternâncias de qualidades simples de tensão e de forma ou repetições de seqüências complexas.

O fluxo de tensão é usado para expressar necessidades, impulsos e sentimentos, está relacionado às pulsões ${ }^{3}$. O fluxo de forma é usado para a entrada ou expulsão de substâncias do ambiente, assim como para a busca ou evitação de estímulos, é usado para expressar conforto ou desconforto e atração ou repulsão, está ligado aos modos de relação com o ambiente. Estes são, segundo Kestenberg, os núcleos motores da incorporação ou expulsão de objetos.

Os ritmos de fluxos de tensão e de forma são considerados por Kestenberg como relacionados ao controle do $i d^{4}$. Com a maturação, esses ritmos se tornam subordinados a fatores motores que vêm sob o controle do ego: os esforços e modelagens no espaço.

Os esforços estão relacionados ao fluxo de tensão e são usados para lidar com o espaço, peso e tempo. Lidam com forças relativamente uniformes, com representações constantes do self e dos objetos, assim eles tendem a estabilizar a motilidade e reduzir a repetição rítmica que é ditada pelas necessidades e disparada pelas mudanças hormonais-metabólicas no organismo.

As modelagens, ligadas ao fluxo de forma, transmitem os tipos de relações com o meio por meio do movimento em planos no espaço.

O esforço e a modelagem aparecem no primeiro ano de vida de forma transitória e rudimentar. Com o desenvolvimento progressivo do ego, eles se tornam mais claros, mais completos e são usados mais freqüentemente. São estabelecidos firmemente no repertório de movimento da criança na fase de latência ${ }^{5}$.

A combinação de padrões complexos de esforço e modelagem é inter-relacionada com o desenvolvimento de uma consciência social pela criança, derivada das identificações, do passado e do presente, com as ações e aspirações dos objetos de desejo.

Segundo Kestenberg, a habilidade de colocar o corpo todo a serviço do fluxo de tensão e esforço, ou do fluxo de forma e modelagem em posturas, está correlacionada com a capacidade de usar todos os agentes psíquicos a serviço das exigências combinadas do id-ego e do superego.

3 Kestenberg e Sossin (1979) utilizam o termo pulsão no sentido freudiano (Freud, 1957), relacionado à representação psíquica das necessidades. Segundo esses autores, cada pulsão possui origem em uma zona corporal específica e processo de descarga, objetivo e objeto determinados.

4 Kestenberg utiliza os conceitos freudianos "ego", "id” e "superego". Estas são as três principais subdivisões funcionais do aparelho mental propostas por Freud. O ego está ligado à racionalidade e às defesas, possui uma parte consciente e uma inconsciente, serve como um intermediário entre o indivíduo e a realidade externa, está numa relação de dependência quanto às reivindicações do id, bem como aos imperativos do superego e às exigências da realidade externa. O id constitui o pólo pulsional da personalidade, os seus conteúdos, expressão psíquica das pulsões, são inconscientes, em parte inatos e em parte recalcados e adquiridos. O superego constitui-se por interiorização das exigências e das interdições parentais. Tem um papel de censor relativamente ao ego, são suas funções a consciência moral, a auto-preservação e a formação de ideais (Laplanche \& Pontalis, 1967/1986; Moore \& Fine, 1990/1992; Rycroft, 1968/1975).

5 Kestenberg utiliza a terminologia da psicanálise freudiana para dividir as fases do desenvolvimento, considerando as fases oral, anal, uretral, genital-interna, fálica, latência e adolescência. 


\section{Ritmos de fluxo de tensão e fatores relacionados}

\section{Ritmos de fluxo de tensão}

Kestenberg esclarece que, por tensão, quer dizer nível de tensão muscular. Assim, um fluxo de tensão livre ocorre quando os agonistas não encontram a contra-ação dos antagonistas. Quando os antagonistas contraem junto com os agonistas, ocorre a detenção do movimento e o fluxo de tensão preso.

A autora acredita que os ritmos de fluxo de tensão fazem parte do aparelho fisiológico congênito que é, no início, independente da psique. Centros hipotalâmicos regulam a ritmicidade dos órgãos e sistemas. Existe uma correlação entre os ritmos secretores e motores. A psique é influenciada e exerce influência nesses processos rítmicos somáticos. Tanto os sistemas musculares involuntários quanto os voluntários estão sujeitos às influências mútuas da soma e da psique. A autora exemplifica uma correspondência básica entre os ritmos motores dos músculos estriados e lisos, citando a interação entre comer e as contrações gástricas.

Os ritmos de fluxo de tensão consistem em certas seqüências de qualidades de tensão que estão bem adaptadas para as necessidades biológicas, como sugar, defecar, urinar e outras. No entanto, o uso desses ritmos não se restringe a essas atividades. O tipo oral de ritmo, por exemplo, está relacionado ao movimento de sugar e à fase oral do nenê, contudo é usado pelo recém-nascido não apenas na zona oral, mas em todo o sistema alimentar.

Segundo a autora, os ritmos orais geralmente continuam sendo os mais freqüentes no decorrer da vida, inclusive na vida adulta. Esses ritmos, além de servirem para a alimentação, estão presentes na fala e influenciam outras partes do corpo. Os ritmos orais tendem à repetição e são usados em ações repetitivas, especialmente nas regiões periféricas do corpo, como rosto e dedos dos pés e das mãos. Dessa forma, deve-se levar em conta o quanto o ritmo oral geralmente excede os outros, antes de se postular que existe uma fixação de determinada pessoa na fase oral.

A diferenciação dos ritmos no nenê se dá com o contato com o ambiente, mediado pela mãe. A pessoa que cuida do nenê irá ajudá-lo a escolher o ritmo apropriado para as diferentes atividades. Dessa forma, ele começa a associar os ritmos motores com as atividades, ele aprende a sugar para obter o leite, a pressionar para defecar e assim por diante.

O aparato do fluxo de tensão é usado para a liberação das pulsões. O nenê começa a representar as necessidades em desejos e assim vai sendo construída uma ponte entre soma e psique. Por meio do fluxo de tensão, as pulsões oral, anal, uretral e genital são expressas em padrões motores.

Em vista das relações entre os ritmos de fluxo de tensão e a expressão das necessidades, Amighi e cols. (1999) consideram que preferências de determinada pessoa por ritmos particulares revelam preocupações da pessoa com necessidades particulares. No entanto, ressaltam que em todos os adultos e crianças típicos, todos os ritmos estão presentes, de forma que as interpretações só podem ser feitas baseadas na frequiência relativa do uso de padrões específicos de movimento e no exame das configurações totais das preferências encontradas, de preferência observando-se a pessoa em ambientes distintos.

\section{Atributos de fluxo de tensão}

Além dos elementos básicos de fluxo de tensão preso e fluxo de tensão livre, Kestenberg observa outras variações nos atributos de fluxo de tensão. São elas: segurar a tensão em um nível uniforme ou ajustes de níveis; alta ou baixa intensidade de tensão; mudança de tensão abrupta ou gradual.

A autora relaciona a regulação dos atributos de fluxo de tensão com o controle dos afetos desenvolvido posteriormente. Considera que os atributos de fluxo de tensão podem ser divididos naqueles que ocorrem mais freqüentemente na frustração e aqueles que indicam alívio e conquista de satisfação.

Dessa forma, o fluxo de tensão preso teria maior relação com sentimentos de cautela e o fluxo de tensão livre com sentimentos de despreocupação. No entanto, Kestenberg ressalta que as nuanças do afeto variam de acordo com a combinação de atributos de fluxo de tensão e outros padrões motores, sendo assim, um atributo de fluxo de tensão pode ser relacionado com uma variedade de sentimentos.

Os atributos do fluxo de tensão provêm componentes importantes na experiência, expressão e comunicação das emoções. Uma vez que o fluxo de tensão está relacionado à expressão das necessidades e à liberação das pulsões, a regulação desse fluxo proporcionada pelos atributos de fluxo de tensão contribui para a formação de defesas contra os próprios afetos. Amighi e cols. (1999) colocam que os atributos do fluxo de tensão introduzem uma medida de controle ou regulação na expressão das necessidades/desejos.

\section{Precursores de esforço}

Kestenberg observa a existência de precursores de esforço como aparatos motores que fazem a mediação entre fluxo de tensão e esforço. São geneticamente e funcionalmente relacionados ao fluxo de tensão e são os suportes motores principais para o aprendizado e os mecanismos de defesa. São orientados tanto para o corpo quanto para o ambiente e estão ligados aos fatores espaço, peso e tempo.

A autora classifica os precursores de esforço em: precursores de abordagem do espaço, são usados para manter a tensão uniforme, o que ajuda a canalizar trajetos do corpo, ou partes dele, no espaço e ajusta os níveis de tensão para conseguir uma mobilidade flexível no espaço; precursores para lidar com o peso, aumentam a intensidade da tensão para produzir ações veementes e diminuem a tensão para expressar gentileza; precursores para lidar com o tempo, mudam de tensão abruptamente para produzir ações repentinas e mudam a tensão gradualmente para expressar hesitação.

A autora observa que os precursores de esforço são usados tanto no aprendizado quanto em mecanismos de defesa. Desenvolvendo essa observação, a autora considera que aprender novas funções envolve o uso de mecanismos de defesa. Nas situações de aprendizado, a pessoa fica receosa quanto à sua integridade física e quanto a ser aprovada pelo professor.

\section{Esforços}

Os esforços são elementos motores da adaptação do ego à realidade externa. São aparatos motores usados para lidar 
com as forças do ambiente (espaço, peso e tempo), que são os fatores essenciais da nossa realidade exterior. São classificados em: diretos e indiretos, ligados ao espaço e ao alcance de nossa atenção; fortes e leves, ligados ao peso e ao grau da nossa intenção; aceleração e desaceleração, ligados ao tempo e aos modos empregados nas tomadas de decisões.

Na Tabela 1, apresentamos de forma esquemática o sistema de movimento dos ritmos de fluxo de tensão e esforços e suas principais interpretações.

Tabela 1. Ritmos de fluxo de tensão e fatores relacionados e suas principais interpretações.

\begin{tabular}{|c|c|}
\hline Padrões de Movimento & Interpretações \\
\hline Ritmos de fluxo de tensão & $\begin{array}{l}\text { Expressam necessidades, } \\
\text { impulsos e sentimentos. } \\
\text { - Estão relacionados às pulsões. }\end{array}$ \\
\hline Atributos de fluxo de tensão & $\begin{array}{l}\text { Provêm componentes } \\
\text { importantes na experiência, } \\
\text { expressão e comunicação das } \\
\text { emoções. } \\
\text { Contribuem para a formação de } \\
\text { defesas contra os próprios afetos. } \\
\text { Introduzem uma medida } \\
\text { de controle ou regulação na } \\
\text { expressão das necessidades } \\
\text { (ritmos de fluxo de tensão). }\end{array}$ \\
\hline Precursores de esforço & $\begin{array}{l}\text { São os suportes motores } \\
\text { principais para o aprendizado e os } \\
\text { mecanismos de defesa. }\end{array}$ \\
\hline Esforço & $\begin{array}{l}\text { - Adaptação do ego à realidade } \\
\text { externa. São usados para lidar com } \\
\text { as forças do ambiente (espaço, } \\
\text { gravidade e tempo). }\end{array}$ \\
\hline
\end{tabular}

\section{Ritmos de Fluxo de Forma e Fatores Relacionados}

\section{Ritmos de fluxo de forma}

Kestenberg classifica o crescimento e encolhimento da forma do corpo como os elementos básicos do fluxo da forma. Acrescenta que existem alterações nos atributos do fluxo de forma que ocorrem em dimensões específicas: largura, comprimento e profundidade do corpo.

Segundo a autora, a alternância rítmica entre crescimento e encolhimento e seus atributos dimensionais é uma auto-regulação altamente diferenciada, ela provê a estrutura para a interação do organismo com o meio. A autora considera que a base do movimento espontâneo e reflexo é o mecanismo de mudar a forma do corpo em resposta a um estímulo, seja ele interno ou externo.

O fluxo de forma está relacionado aos modos de relação. Os atributos do fluxo de forma agem na regulação das relações da pessoa consigo mesma e com os objetos.

Kestenberg classifica o fluxo de forma em bipolar (simétrico), unipolar (assimétrico) e design de fluxo de for$m a$; todos eles já estão presentes no recém-nascido, mas são sujeitos a mudanças durante o desenvolvimento.

\section{Fluxo de forma bipolar}

Segundo Amighi e cols. (1999), o fluxo de forma bipolar refere-se a padrões de crescer e encolher de uma forma simétrica. Formas em crescimento são modos de tornar-se acessível (abrir-se) e geralmente refletem sentimentos bons ou de conforto. Formas em encolhimento são meios de isolar-se (fechar-se) e geralmente refletem sentimentos de desconforto. O fluxo de forma bipolar pode ocorrer em três dimensões: a horizontal, a vertical e a sagital.

Os autores colocam que freqüentemente avaliamos os sentimentos dos outros com base em suas mudanças bipolares de forma. Particularmente no rosto, mas no tronco também.

\section{Fluxo de forma unipolar}

Quando as mudanças na forma do corpo são assimétricas, Kestenberg chama de fluxo de forma unipolar. Essa qualidade de movimento é usada principalmente na reação a estímulos específicos provindos do meio ambiente.

\section{Design de fluxo de forma}

Kestenberg caracteriza os designs de fluxo de forma em termos de movimentos centrífugos ou centrípetos e em termos de espaço perto, intermediário, ao alcance e espaço geral.

$\mathrm{O}$ design de fluxo de forma provê um modo de a pessoa orientar-se no espaço, pegando o próprio corpo como um ponto focal de partida e retorno. "Para longe de mim" e "para mim" são conceitos nascidos da percepção dos movimentos centrífugos e centrípetos.

Para Kestenberg, as influências culturais tendem a atuar no design de fluxo de forma mais do que atuam em qualquer outro padrão. Contudo, podem ser notadas no nascimento algumas preferências congênitas por determinados designs de fluxo de forma.

\section{Modelagens no espaço em direções e em planos}

Segundo Kestenberg, a passagem do fluxo de forma para as modelagens em direções e planos significa a passagem da regulação das relações consigo mesmo e com os objetos, para o controle do aprendizado, das defesas e relações com objetos constantes.

Enquanto os padrões de fluxo de tensão, de precursores de esforço e de esforço são modos e qualidades que têm pouca relação com os objetos, os padrões de fluxo de forma e de modelagem do espaço são facilmente modificados em decorrência de imitação, identificação e ajustamento com as pessoas. São os padrões de fluxo de forma e de modelagem do espaço que dão estrutura aos padrões de fluxo de tensão e esforço.

Kestenberg relaciona os movimentos de fluxo de forma $\mathrm{e}$ modelagens em direções e planos, com a construção da imagem corporal. Considera que os sentimentos de ser grande ou pequeno, de estar confortável ou desconfortável, as sensações agradáveis e desagradáveis em várias partes do corpo (que cresce em direção a alguns estímulos e encolhe-se em direção a outros) e a capacidade de colocar o corpo em perspectiva na relação com o espaço que o circunda são passos importantes na criação da imagem corporal. Ela acrescenta que isso não pode ser conseguido sem a construção simultânea da imagem de um objeto do qual a pessoa se diferencia.

Assim, a autora considera que o fluxo de forma tem um papel decisivo no desenvolvimento do núcleo corporal das imagens de si mesmo e dos outros. A modelagem no espaço 
torna-se uma parte integral da complexa inter-relação entre os objetos, não apenas aqueles percebidos fora, mas também suas imagens internalizadas.

A modelagem do espaço em direções é usada para estabelecer ou descontinuar pontes com os objetos. Quando o movimento prossegue em direções, o espaço é dividido em linhas que formam pontes até os objetos ou abandonam o contato. O movimento pode ser nas seguintes direções: transversalmente e lateralmente (horizontalmente); para baixo e para cima (verticalmente); para frente e para trás (sagitalmente).

As modelagens do espaço em planos são determinadas por pelo menos duas dimensões. Cada plano é usado de uma maneira diferente para melhor servir algumas funções do ego que têm um papel nas relações: horizontal - uma pessoa pode fechar-se em pequenas áreas ou expandir-se em uma grande área do espaço, este plano é usado para explorar os objetos; vertical - uma pessoa pode ascender ou descender, unindo as direções vertical e lateral, para confrontar os objetos; sagital - a pessoa retrocede ou avança (unindo as direções frente/trás e alto/baixo) em antecipação às atitudes das outras pessoas.

Na Tabela 2, apresentamos o sistema de movimento dos ritmos de fluxo de forma e modelagens e suas principais interpretações.

\section{Afinidades e Choques entre Padrões de Movimentos}

\section{A afinidade entre os padrões de movimento usados por duas pessoas é a base da empatia:}

A sintonia entre as pessoas é baseada na similaridade ou afinidade de seus padrões. Uma criança se sente como um ['at one' no original] com sua mãe quando ambos usam atributos de fluxo de tensão e de fluxo de forma idênticos. A empatia é baseada no uso de padrões que têm afinidade, não necessariamente idênticos (Kestenberg \& Sossin, 1979, p. 72, tradução nossa).

Em geral, o ego da mãe seleciona elementos de esforço que são derivados e têm afinidade com os atributos de fluxo de tensão que a criança usa a cada momento. A sintonia entre mãe e filho precisa ser adequadamente orientada para funções específicas para ser adaptativa. A mãe não deve apenas se sintonizar com o filho, mas também ensiná-lo a sintonizar-se com ela.

Quando há choques constantes e intensos entre mãe e filho, com pouca ou nenhuma sintonia, eles podem diminuir a capacidade da criança de acomodação e conduzir a uma inibição e restrição das funções. No entanto, um excesso de sintonia também pode ser prejudicial à criança, vindo a atrasar o processo de diferenciação. Portanto, é necessário que haja um equilíbrio entre choques e sintonia na relação entre mãe e filho.

Algumas crianças sintonizam melhor com os pais e avós do que com as mães. Nesses casos, quando a mãe vai para o trabalho, a criança pode começar a florescer com uma pessoa mais compatível que tome conta dela.

Essas relações de sintonia ou não-sintonia não se restringem às crianças e às relações familiares, elas ocorrem, em
Tabela 2. Ritmos de fluxo de forma e fatores relacionados e suas principais interpretações.

\begin{tabular}{|c|c|}
\hline Padrões de movimento & Interpretações \\
\hline Ritmos de fluxo de forma & $\begin{array}{l}\text { - Expressam sentimentos de relação } \\
\text { com o meio e consigo mesmo } \\
\text { (conforto/desconforto; atração/ } \\
\text { repulsão). } \\
\text { - Estão ligados aos modos de relação } \\
\text { com o ambiente. }\end{array}$ \\
\hline Fluxo de forma bipolar & $\begin{array}{l}\text { Refere-se a padrões de crescer e } \\
\text { encolher de uma forma simétrica. } \\
\text { Formas em crescimento são modos } \\
\text { de se tornar acessível (abrir-se); } \\
\text { formas de encolhimento são meios de } \\
\text { se isolar (fechar-se). }\end{array}$ \\
\hline Fluxo de forma unipolar & $\begin{array}{l}\text { Refere-se a mudanças assimétricas } \\
\text { na forma do corpo. } \\
\text { É usado principalmente na reação } \\
\text { a estímulos específicos provindos do } \\
\text { meio externo. }\end{array}$ \\
\hline Design de fluxo de forma & $\begin{array}{l}\text { São os movimentos centrífugos ou } \\
\text { centrípetos. } \\
\text { "Para longe de mim" e "para mim" } \\
\text { são conceitos nascidos da percepção } \\
\text { dos movimentos centrífugos e } \\
\text { centrípetos. }\end{array}$ \\
\hline $\begin{array}{l}\text { Modelagens no espaço em } \\
\text { direções e em planos }\end{array}$ & $\begin{array}{l}\text { Relacionam-se ao controle do } \\
\text { aprendizado, das defesas e relações com } \\
\text { objetos constantes. } \\
\text { A modelagem do espaço em } \\
\text { direções é usada para estabelecer ou } \\
\text { descontinuar pontes com os objetos. } \\
\text { A modelagem do espaço em planos } \\
\text { está associada a algumas funções do } \\
\text { ego que têm um papel nas relações: }\end{array}$ \\
\hline
\end{tabular}

maior ou menor grau, em qualquer situação na qual estivermos em contato com outro ser humano.

\section{Afinidades dentro dos sistemas de movimento e entre eles}

Os sistemas de movimento são o fluxo de tensão e esforços e fluxo de forma e modelagens. O primeiro lida com as necessidades (internas e externas) e o outro com as relações (da pessoa consigo mesma e com os outros).

Uma afinidade geral no sistema de fluxo de tensão e esforço existe quando ou os atributos de 'lutar' ou os atributos de 'ceder' se combinam em uma ação. Assim padrões afins dão suporte a objetivos agressivos ou de sustentação da vida. No sistema de fluxo de forma e modelagem todos os padrões de forma fechada apóiam o objetivo de reduzir a exposição enquanto os padrões de forma aberta se combinam para aumentar a exposição (Kestenberg \& Sossin, 1979, p. 73, tradução nossa).

Afinidades dentro de um sistema de movimento (por exemplo, dentro do sistema de fluxo de tensão e esforços) são chamadas verticais. A seleção de padrões homogêneos, com afinidades verticais específicas, é uma função do ego. Afinidades entre os dois sistemas são chamadas horizontais. São baseadas na compatibilidade entre lutar com formas fechadas e ceder com formas abertas. 
Os choques e harmonias são aspectos intrínsecos do processo de variação do movimento. $\mathrm{O}$ ego não apenas age como mediador entre componentes adversários, como cria conflitos.

Nas Tabelas 3 e 4, expomos esquematicamente os principais aspectos ligados aos sistemas de movimento fluxo de tensão e esforços e fluxo de forma e modelagens respectivamente.

Tabela 3. Sistema de movimento fluxo de tensão e esforços e seus principais aspectos.

\begin{tabular}{|c|c|c|c|}
\hline $\begin{array}{l}\text { Padrão de } \\
\text { movimento }\end{array}$ & $\begin{array}{l}\text { Agência } \\
\text { psíquica }\end{array}$ & Relações & $\begin{array}{c}\text { Atributos do } \\
\text { movimento }\end{array}$ \\
\hline $\begin{array}{l}\text { Ritmos de fluxo } \\
\text { de tensão }\end{array}$ & id & \multirow{3}{*}{$\begin{array}{l}\text { Lidam com as ne- } \\
\text { cessidades internas e } \\
\text { externas }\end{array}$} & \multirow{3}{*}{ lutar/ceder } \\
\hline $\begin{array}{l}\text { Precursores de } \\
\text { esforço }\end{array}$ & ego & & \\
\hline Esforços & ego & & \\
\hline
\end{tabular}

Tabela 4. Sistema de movimento fluxo de forma e modelagens e seus principais aspectos.

\begin{tabular}{lccc}
\hline \multicolumn{1}{c}{$\begin{array}{c}\text { Padrão de } \\
\text { movimento }\end{array}$} & $\begin{array}{c}\text { Agência } \\
\text { psíquica }\end{array}$ & \multicolumn{1}{c}{ Relações } & $\begin{array}{c}\text { Atributos do } \\
\text { movimento }\end{array}$ \\
\hline $\begin{array}{l}\text { Ritmos de fluxo } \\
\text { de forma }\end{array}$ & id & $\begin{array}{l}\text { Expressam as relações da } \\
\text { pessoa consigo mesma e } \\
\text { com o meio }\end{array}$ & abrir/fechar \\
$\begin{array}{l}\text { Modelagens em } \\
\text { direções e em } \\
\text { planos }\end{array}$ & ego & com & \\
\hline
\end{tabular}

\section{Afinidades e choques verticais}

Cada um dos subsistemas pode ser usado para a expressão de conflito por combinações entre ceder e lutar ou de formas abertas e fechadas. Choques entre os atributos de lutar e ceder no subsistema de fluxo de tensão e entre os atributos de formas abertas e formas fechadas no subsistema do fluxo de forma refletem conflitos entre os sentimentos. $\mathrm{O}$ ego só pode assumir um controle limitado sobre os sentimentos que estão ligados de perto às necessidades corporais; esses conflitos entre sentimentos são originados no id.

Conflitos entre os elementos de lutar e ceder nos subsistemas de precursores de esforço ou nos esforços, e entre os elementos de formas abertas e fechadas nos subsistemas de modelagem em direções e modelagem em planos refletem conflitos no ego. Esses conflitos operam entre defesas incompatíveis, como identificação com o agressor e escape ou barrar o acesso para o agressor e aumentar os limites de contato para ele ao mesmo tempo. Eles também ocorrem como a incompatibilidade entre duas funções adaptativas do ego, como em direcionar a atenção e ir mais devagar, ou nas funções do ego de orientação para si mesmo e orientação para o objeto, como abraçar alguém e olhar para outro alguém.

\section{Afinidade e choques horizontais}

Existem mudanças no fluxo de tensão que não são acompanhadas por mudanças no fluxo de forma e vice-versa, quando isso acontece há um desequilíbrio entre os padrões de fluxo de tensão e forma. No primeiro caso, falta estrutura e, no segundo, impacto dinâmico. Além dessa possibilidade de desequilíbrio, existem situações em que ocorrem choques entre fluxos de tensão e forma, exemplificadas nas formas abertas com tensões presas ou formas fechadas com tensões livres.

O fluxo de tensão reflete as necessidades corporais e o fluxo de forma é mais dependente das influências externas, a repetição rítmica de suas combinações expressa a congruência ou incongruência, o equilíbrio ou desequilíbrio, entre as respostas aos estímulos internos e as respostas aos estímulos externos. $\mathrm{O}$ quanto mais afins essas combinações, o menos propenso a conflitos é o indivíduo.

A combinação harmoniosa entre esforço e modelagens é uma aquisição tardia. Ela se desenvolve gradualmente e não se torna consolidada antes da fase de latência.

\section{Gestos e posturas}

Na visão de Kestenberg, no gesto, apenas algumas partes do corpo são colocadas a serviço de um dado padrão de movimento. Já no movimento postural, todas as partes do corpo ficam envolvidas em uma ação que serve para a implementação de um padrão.

Os padrões de esforço e modelagens do espaço em gestos são relacionados por Kestenberg a regulagens feitas pelo ego, enquanto que esses padrões, atuando nas posturas, refletem a influência do superego no controle do ego da motilidade.

Assim, a fusão ou choque entre os padrões de movimento nos gestos e posturas são indicadores de harmonia ou conflito entre o ego e o superego. A combinação ou não combinação dos padrões de movimento dentro dos gestos e posturas são indicadores de harmonia ou conflito dentro do ego e do superego respectivamente.

Além dos choques e fusões entre os padrões de movimento nos gestos e posturas, também podem ocorrer equilíbrios e desequilíbrios. Os desequilíbrios ocorrem quando ou um padrão de modelagem não é acompanhado por um padrão de esforço relacionado ou um padrão de esforço não é acompanhado por um padrão de modelagem relacionado.

\begin{abstract}
Se os padrões de modelagem não estão equilibrados por padrões de esforço relacionados, nós nos referimos a isto como 'forma sem conteúdo', ou como expressivo de relações com os objetos sem o suporte de qualidades dinâmicas, reveladas no esforço. Se os elementos de esforço não estão equilibrados por elementos de modelagem relacionados [...], a estrutura para uma ação dinâmica está faltando; nós assumimos que um tipo particular de adaptação à realidade desenvolveu-se sem uma relação a um objeto e é independente de objetos. Enquanto a não combinação expressa um tipo especial de conflito ou no ego ou no superego, o desequilíbrio implica um retardamento ou incompletude da estrutura (Kestenberg \& Sossin, 1979, p.105, tradução nossa).
\end{abstract}

\section{Preferências Iniciais por Certos Ritmos de Movimento e suas Influências nos Padrões de Movimento da Vida Adulta}

As preferências por certos ritmos de movimento podem ser detectadas desde cedo e também podem ser reconhecidas na vida adulta, na qual aparecem freqüentemente em ritmos misturados. Ritmos encorajados pela mãe ou aumentados por forças biológicas específicas da fase (não só fase do 
desenvolvimento, como também fases decorrentes de fatos da vida adulta como, por exemplo, gravidez ou doença) aparecem freqüentemente em ritmos puros. Algumas vezes, os bebês mostram preferências claras por certos ritmos, sejam eles puros ou misturados, enquanto outras vezes podem ser detectadas certas constelações rítmicas que podem ser definidas em termos de proporções entre os ritmos, seqüências e mutabilidade.

Como vimos, o sistema de movimento do fluxo de tensão e esforço está relacionado às necessidades internas e externas da pessoa. Assim, a linha de desenvolvimento dos atributos do fluxo de tensão para os precursores de esforços e esforços sugere que afetos específicos, experienciados na infância, têm um papel na escolha posterior de modos de adaptação à realidade externa.

Por sua vez, o sistema de movimento do fluxo de forma e modelagens expressa as relações da pessoa consigo mesma e com o meio. O campo do fluxo de forma e modelagens no espaço em direções e em planos fala sobre a linha de desenvolvimento das primeiras formas para as formas posteriores de relacionamento por meio do movimento. Dessa forma:

\footnotetext{
Temperamentos ou modos persistentes de regulação do afeto podem influenciar escolhas futuras de defesas e mecanismos de lidar com o ambiente e sentimentos a respeito de si mesmo podem promover seletivamente certas formas de aproximação e relacionamento com os objetos (Kestenberg \& Sossin, 1979, p. 109, tradução nossa).
}

\section{Considerações Finais}

Kestenberg traz à tona a relação entre o desenvolvimento dos padrões motores e o desenvolvimento da psique, assim como as origens dos padrões de movimento dos adultos em suas experiências e preferências da primeira infância. Indo além do aspecto de comunicação não-verbal do movimento, a autora encara-o como constituinte da pessoa, desdobrando seus significados. Também fica evidente como os ritmos de movimento influenciam no modo de pensar da pessoa e se relacionam de perto com seus sentimentos e sua personalidade.

As pesquisas de Kestenberg são pouco difundidas no Brasil, entre a literatura nacional, apenas em Cabral (2001) foi encontrada uma menção a essas pesquisas. Cabral (2001) destaca aspectos dessas investigações enfocando as relações entre mãe e filho.

Os estudos de Kestenberg vêm ao encontro de uma necessidade atual de aprofundar a compreensão do movimento humano, por meio de dados consistentes sobre os entrelaçamentos entre o mover e o afeto. O movimento em Kestenberg é reconhecido como um fenômeno que evidencia a todo momento a singularidade dos sentidos de cada ser humano.

Kestenberg apresenta a interferência dos mecanismos de defesa no movimento, mediante os precursores de esforço e modelagens em direções que modulam os ritmos de fluxo de tensão e de forma. Os precursores de esforço caracterizam a criação de tensões usadas na proteção do organismo contra estímulos internos e externos. As modelagens em direções dão forma ao corpo protegendo-o contra estímulos externos.

Essa noção tem relação com o que é dito por outros autores sobre as tensões musculares que bloqueiam a expressão de necessidades internas, tensões estas que acabam por "moldar" o corpo (o que Kestenberg denomina "atitude corporal"), caracterizando modos próprios de posicionar-se e movimentar-se.
Penna (1990) considera que "a origem psicológica do movimento são as pulsões, as tendências e os desejos expressos nas tensões corporais e revelados na linguagem dos gestos e dos sons humanos" (p. 171). Baseando-se em Sapir (1964 citado por Penna, 1990), a autora fala que os desejos se manifestam corporalmente na procura pelo objeto de satisfação, mas a tensão corporal pode bloquear a expressão do desejo. Penna (1989) menciona a teoria da “couraça muscular do caráter" de Reich (1957), ao considerar que a socialização faz com que o sujeito, ao longo de sua vida, vá adquirindo tensões excessivas em determinados segmentos de seu corpo, conseqüência dos atos não realizados.

Outro aspecto relevante dos estudos Kestenberg diz respeito às relações entre os corpos. Kestenberg enfoca a importância da sintonia entre os movimentos de mãe e filho, entre coleguinhas, entre terapeuta e paciente, observador e observado e outros.

Amighi e cols. (1999) definem a sintonia corporal como a mistura ou adaptação dos ritmos àqueles de outra pessoa. Assim, a sintonia permite à mãe e ao nenê, por exemplo, a convivência em harmonia. Kestenberg e Sossin (1979) colocam que a sintonia no fluxo de tensão entre duas pessoas está relacionada à empatia e o ajuste no fluxo de forma relaciona-se à confiança mútua.

Sintonizar-se e ajustar-se à outra pessoa, compartilhando com ela os mesmos ritmos de fluxos de tensão e de forma, ou ritmos afins, cria o fundamento para a empatia no estabelecimento de um relacionamento. Além disso, favorece a comunicação e, por conseguinte, o entendimento do movimento do outro.

Segundo Schilder (1950/1999), se uma pessoa vê outra se movendo, tem estes movimentos evocados em seu próprio corpo. Reed e Farah (1995) verificaram, mediante experimentos, que um mesmo esquema corporal é usado para processar as informações relativas ao próprio corpo e para processar informações relativas aos corpos dos outros.

Segundo Penna (1989), existe uma tendência atualmente a introduzir técnicas corporais nas psicoterapias. A autora aponta que isso altera a relação psicoterapêutica:

[...] técnicas de mobilização da sensibilidade e dos movimentos do paciente, subverteram a antiga relação terapêutica, introduzindo o contato proximal entre o terapeuta e seu paciente, [este fato] provoca a reformulação do conceito de transferência e pede que o profissional esteja muito consciente do seu próprio corpo em relação com o outro (p. 1).

Dosamantes (em entrevista cedida a Fairweather, 1994) relata que os movimentos dos pacientes em terapias somatopsíquicas podem despertar no terapeuta momentos da vida dele que, de alguma forma, se assemelham aos momentos pelos quais os pacientes estão passando. O terapeuta pode, nesse processo, considerar suas próprias experiências pessoais e reações corporais no contato como os pacientes como referências para facilitar o conhecimento da etapa do processo no qual os pacientes estão durante o tratamento. Segundo Dosamantes, esse processo é chamado de contra-transferência. Ambra (1995) também levanta esse ponto e afirma que o terapeuta deve ser muito cuidadoso nesse processo de contra-transferência.

Scaer (2001) também aborda a importância das relações corporais entre o terapeuta e o paciente, focando a cura de traumas. De acordo com ele, os sintomas físicos decorrentes 
do trauma devem ser tratados pelo terapeuta como legítimos e significativos.

Fica evidente que as considerações de Kestenberg trazem parâmetros necessários para quem trabalha em uma perspectiva psicossomática. A autora relaciona o impulso que move o corpo à qualidade do movimento. Na perspectiva adotada por ela, os ritmos de movimento predominantes nos padrões de movimento de determinada pessoa podem nos fornecer dados sobre etapas iniciais da vida da pessoa. Longe de ser simplificadora, Kestenberg traz um sistema complexo para a análise do movimento do outro. Por meio de seus estudos fica evidente a importância do terapeuta atentar para seu próprio corpo no processo de permitir a expressão do corpo do outro. A configuração de seu corpo é importante para fornecer um ambiente receptivo e seguro para acolher os ritmos de movimento do outro.

\section{Referências}

Ambra, L. N. (1995). Approaches used in dance/movement therapy with adult women incest survivors. American Journal of Dance Therapy, 17(1), 15-24.

Amighi, J. K.; Loman, S.; Lewis, P. \& Sossin, M. (1999). The meaning of movement: developmental and clinical perspectives of the Kestenberg Movement Profile. New York: Routledge.

Cabral, S. V. (2001). Psicomotricidade relacional: prática clínica e escolar. Rio de Janeiro: RevinteR.

Damásio, A. R. (1996). O erro de Descartes. (D. Vicente e G. Segurado, Trads.) São Paulo: Companhia das Letras. (Trabalho original publicado em 1994)

Fairweather, P. (1994). An interview with Dosamantes, Irma. American Journal of Dance Therapy, 16(1), 13-19.

Freud, S. (1957). Instincts and their vicissitudes. Em S. Freud (Org.), Standard Edition, 14 (pp. 109-140). London: Hogarth Press.

Kestenberg, J. S. (1975). Children and parents: psychoanalytic studies in development. New York: Jason Aronson.
Kestenberg, J. S. \& Sossin, K. M. (1979). The role of movement patterns in development 2. New York: Dance Notation Bureau Press.

Laban, R. (1978). Domínio do movimento. (A. M. B. de Vecchi e M. S. M. Netto, Trads.). São Paulo: Summus. (Trabalho original publicado em 1971)

Laplanche, J. \& Pontalis J. B. (1986). Vocabulário da psicanálise. (P. Tamen, Trad.) Santos: Martins Fontes. (Trabalho original publicado em 1967)

Moore, B. E. \& Fine, B. D. (1992). Termos e conceitos psicanalíticos. (J. O. A. Abreu, Trad.). Porto Alegre: Artes Médicas. (Trabalho original publicado em 1990)

Penna, L. (1989). Além da fronteira desgastada: o significado do movimento. Boletim de Psicologia, 39(90/91), 1-12.

Penna, L. (1990). Imagem corporal: uma revisão seletiva da literatura. Psicologia USP, 1(2), 167-174.

Reed, C. L. \& Farah, M. J. (1995). The psychological reality of the body schema: a test with normal participants. Journal of experimental psychology: human perception and performance, 21(2), 334-343.

Reich, W. (1957). Analysis del Caracter. Buenos Aires: Paidós.

Rycroft, C. (1975). Dicionário crítico de psicanálise. (J. O. A. Abreu, Trad.). Rio de Janeiro: Imago. (Trabalho original publicado em 1968)

Scaer, R. C. (2001). The body bears the burden: trauma, dissociation, and desease. New York: The Haworth Medical Press.

Schilder, P. (1999). A Imagem do corpo: as energias construtivas da psique (R. Wertman, Trad.). São Paulo: Martins Fontes. (Trabalho original publicado em 1950)

Stinson, S. W. (1995). Body of Knowledge. Educational theory, 45(1), 43-54.

Recebido em 17.02.2006

Primeira decisão editorial em 16.06.2007

Versão final em 10.09.2007

Aceito em 03.03.2008 